\title{
A new sensor for dry rot: On-site detection of fungal metabolites using colour visualisation technology
}

Received (in revised form): 19th July, 2005

\section{George McGill}

is a graduate in botany from Glasgow University where he specialised in plant biochemistry and fungal genetics. He has worked in the building preservation industry since 1977 and has served as a researcher survey or manager, managing director and now as an independent consultant. $\mathrm{He}$ is a member of the British Mycological Society, the International Research Group on Wood Preservation and is an Associate of the Institute of Wood Science. He is based in Glasgow and provides training, independent advice and expert witness services throughout the UK.

\begin{abstract}
A greater understanding of the fundamental processes involved in wood decay has led to the development of new technology for detecting and ascertaining the spread of dry rot in buildings. This technology can save many thousands of pounds of exposure work usually associated with finding dry rot. In addition, the early detection of dry rot before any wood decay takes place offers increased opportunities for conservation and preserving important historic and cultural building features. The new dry rot sensing technology, without the usual disruption to the building fabric and features, tells when dry rot and conditions for it are present, if it is dead or active and how far it has spread and whether any treatment for it has been effective.
\end{abstract}

\section{Keywords:}

dry rot, fungal decay, sensor, fungal metabolites, colour visualisation, buildings

McGill Consultancy Ltd 35 Cleveden Road Glasgow G12 oPH, UK Tel: + 44 (o) 1413571931 Fax: + 44 (0)1040576 0441 E-mail: mcgill.consultancy@ ntlworld.com

Website: www.mcgill-consultancy. co.uk

\section{BACKGROUND}

Dry rot, the decay of timber by the fungus Serpula lacrimans, is the most serious timber decay problem in buildings in the UK and other temperate regions. When environmental conditions permit (usually resulting from a failure in building maintenance) the fungus decays timber components and, without remedial action, considerable structural damage can ensue. Damage may be considerable and extend far beyond structural elements to valuable artefacts such as ornamental plasterwork and timber panelling. The unique ability of the dry rot fungus to penetrate the non-timber elements of buildings, such as masonry and plaster, in the form of 


\section{Current procedures in use for detection of timber rot}

\section{Development of low- cost and reliable detecting technology has previously proved elusive}

mycelial strands, and to transport water through those strands, allows the fungus to spread considerable distances from its point of origin.

The conditions for growth and development of the fungus are usually present in locations within the building that are not immediately accessible. The detection of rot is therefore difficult and assessment of the extent to which it has developed usually involves disruptive investigation. Such disruptive investigation can involve damage to valuable features.

The current procedures in common use for the detection of timber rot in buildings are broadly those described in the technical literature like publications from the Building Research Establishment (1993) and Bricknell (1976, 1991). These procedures typically involve visual inspection and probing, sometimes supplemented by moisture measurement usually using an electronic meter. Further investigation typically involves the uplifting of floors and removal of plasterwork, panelling or other building components in an attempt to see how far the condition has spread.

More recently, the availability of more sophisticated instrumentation such as fibre-optic cameras and endoscopes has enabled some visual observation of concealed areas to be made. The detection of volatile metabolites by using sniffer dogs has been used in the UK and Denmark (Lloyd and Singh, 1994; Bech-Andersen, 1995). The detection of volatile metabolites by electronic equipment has also received attention in recent years (Esser and Tas, 1992). It seems, however, that the complexity of the range of compounds together with the broadly similar volatile profiles emitted by decay organisms has necessitated the use of elaborate and expensive equipment. Such equipment, at least at present, is too complex and expensive for routine survey work.

The development of low-cost and reliable detecting technology has proved elusive until a recent focus on the detection of biochemical metabolites. The detection of biochemical metabolites using colorimetric methods has proved to be very useful as a result of its being specific and reliable together with being inexpensive. Although the metabolites produced by the dry rot fungus Serpula lacrimans are similar in many ways to those produced by most wood-destroying fungi, the conditions under which they are produced within a building are very different, which allows the specific detection of dry rot. The specificity of this technology in respect of dry rot is largely due to two main factors:

- the unique and narrow range of moisture conditions that support dry rot development in buildings;

- the metabolites being detected are only produced by the fungus in the presence of wood; they are substrate induced.

It has been known for many years that the dry rot fungus brings about changes in its immediate environment as it grows and develops. It is only comparatively recently, however, that the significance of some of these has become well enough understood to enable them to be exploited commercially. In particular, the biochemistry of wood decomposition, while still not fully understood, is understood well enough to enable the 
Development of dry rot within buildings is dependent on conditions for fungal growth and development being present

Five-stage procedure detection of certain biochemicals to be used to map out the spread of fungal growth in buildings, especially those biochemicals that are produced at the very early stages of wood decay. The detection of such compounds offers the prospect of being able to detect the presence of dry rot in a building before serious wood decomposition takes place, thereby increasing the opportunity to implement a conservation-oriented approach to dry rot repair. There are clearly enormous benefits in adopting such an approach. It offers not only the chance to save on the cost of repair but also the ability to retain features of the building that are of historic and cultural importance.

In all cases, timber rot including dry rot arises as a result of water ingress. Water ingress and the resulting spread of dampness through the fabric are the principal means by which timber rot conditions are initiated and sustained. It is therefore essential that an accurate spread of moisture throughout the building fabric can be ascertained. The assessment of moisture content in buildings is complicated by the differing waterholding capacity of the components of the building fabric. Different materials have a different natural water-holding capacity. Experience shows that surface moisture readings recorded with an electronic meter do not correlate well with readings recorded directly from within the fabric of a lath and plaster wall. It is of fundamental importance to measure the free moisture (or moisture available to initiate and sustain fungal colonisation and growth) not simply the total moisture which might include natural water such as water of crystallisation, or water absorbed into the fabric as a result of natural or contaminant-induced hygroscopicity. Problems of structural dampness or moisture ingress through flues or rising dampness can lead to contamination of the building fabric and to an increase in the natural water-holding capacity of a substrate by the presence of hygroscopic salts. Such salts enhance electrical conductivity and lead to erroneous readings when electronic moisture meters are used. Sensors will absorb only the free moisture within the location in which they are installed. The free moisture is the moisture available to the dry rot fungus to break down the wood.

The development of dry rot within a building is wholly dependent on the conditions for fungal growth and development being present. On a practical level, moisture is the most important growth requirement for the development of dry rot in buildings. When moisture conditions are present within the narrow range that supports dry rot the sensor will detect biochemical metabolites produced by the fungus in the first stages of cellulose decomposition and before wood decay takes place. Dry rot therefore can be detected early enough to permit beams that are affected, but not yet decayed, to be conserved.

\section{PROCEDURE}

There are five stages in the procedure as described below. Sensors are installed in small, pre-drilled holes within the areas of wood masonry or plaster identified as being at risk. They are monitored usually for about two weeks during which time they reach equilibrium with the building substrates and react to the presence of the dry rot fungus. Sensors installed 
Understanding of the nature of the growth and development of the fungus has driven new technology beyond the 'at risk' areas will confirm that there is no dry rot activity. There is no need to uplift floors or to remove plasterwork. The extent of the spread of dry rot can be determined from examination of the sensors. Thus, to summarise:

- fit sensors;

- allow to equilibrate;

- examine sensors;

- record affected areas and 'at risk' areas;

- monitor 'at risk' areas for a further period.

This new technology has been developed as a result of a greater understanding of the fundamental nature of the growth and development of the fungus and the way in which it breaks down wood. It is based on the biochemical principles that underpin the mechanism of action of the decomposition of wood.

\section{HOW THE TECHNOLOGY WORKS}

Organic acids, in particular oxalic acid, are considered to form part of a non-enzymic process of cellulose decomposition that contributes to the complex wood decay process. Oxalic acid is produced in large quantities by the dry rot fungus and some other wood decay fungi. The precise nature of the process of cellulose decomposition remains unclear but it is considered likely that the oxalic acid functions as a catalyst to enable a hydrolysis reaction to take place within the crystalline lattice of the cellulose component of the wood cell wall. The oxalic acid seems to facilitate hydrolysis of the glycosidic bonds of cellulose chains as a first stage in a multi-component cellulase system. This first stage enables the multi-component cellulase enzyme systems to gain access to the cellulose polymer chains. The enzymic components of the cellulase complex are too large to be able to penetrate the capillary structure of the cell wall. It is clear that brown rot and many white rot fungi produce organic acids, especially oxalic acid, and that this plays a part in the microbial decomposition of the cellulose cell wall. The cellulose component of wood cell walls represents around 30 per cent of the structure by weight of most softwoods. The detection of oxalic acid produced by Serpula lacrimans in parts of a building where there is a sufficiency of free moisture has proved to be a reliable and reproducible aid in the detection of dry rot in those parts of the structure concealed from view.

The early detection of wood decay by examining colour change has been noted previously. Rypacek (1966) and Willeitner and Peek (1979) were able to detect fungal growth in wood before there was any visible evidence of decay or any substantial (greater than 1 per cent by weight) weight loss. It was further reported by Peek et al. (1980) who recorded a colour change reaction with 22 species of fungi responsible for brown rot (all the species under test) and 15 out of 25 species of fungi causing white rot.

The difficulty in using this principle in practice as an on-site survey procedure is partly because there is great variability in the natural acidity of wood in service. In addition, wood contains a large number of 


\section{Sensors have passed independent tests}

\section{Benefits of the new technology}

\section{A simple procedure}

extraneous substances that interfere with both moisture absorption and desorption, and the colour change that enables visualisation. These difficulties have been overcome, however, by using a pre-conditioned, vacuum-impregnated, wood sensor manufactured from a carefully selected type of wood. A period of pre-conditioning is required to remove the extraneous substances that interfere with the colour change.

After pre-conditioning and vacuum-impregnation with the colour reagent the absorption and desorption of moisture, and the colour change reaction, can take place reliably and reproducibly in the presence of Serpula lacrimans. Independent testing of the sensors has been carried out at The University of Leeds. All the tests have verified that the sensors function reliably and reproducibly, and that clear visual colour change can be observed a very short time after the sensors are exposed to active colonies of the dry rot fungus. The time taken to change colour is usually between four and ten days.

\section{BENEFITS}

The benefits conferred by this new technology are too many to number, but the following are a few obvious ones:

- no need for disruptive surveys;

- cornices can be saved;

- ornamental woodwork can be saved;

- 'at risk' areas can be tested;

- the full extent of the spread of dry rot can be mapped out;

- growth can be monitored;

- activity or non-activity of dry rot can be confirmed;

- environmental control methods can be implemented and evaluated;

- the success of the remedial work can be verified.

\section{HOW TO USE THE SENSORS}

The procedure involves placing special sensors in areas that are affected by dry rot or are at risk of becoming affected by dry rot and examining them from time to time to see if they have undergone a colour change. It is really that simple; in fact, it is simple, reliable, neat and inexpensive. The technology in action is illustrated in Figures 1-3.

The sensor is especially useful if a surveyor is suspicious of a location within a building and feels that more information is needed. For example, this can happen in a situation where there is a stain in plasterwork that seems to have arisen from an ingress of moisture. Sensors placed adjacent to structural timbers that might be at risk from dry rot can detect if decay has started or is about to start. Appropriate intervention then can be implemented. Similarly, in the event of a typical domestic flood from a washing machine or toilet overflow, the affected area can be tested to ensure that dry rot does not develop as the area dries out.

Sensors are also appropriate when it is necessary to collect detailed information about the spread of moisture within a building and to map out the areas affected by dry rot or that might become affected by dry rot. 


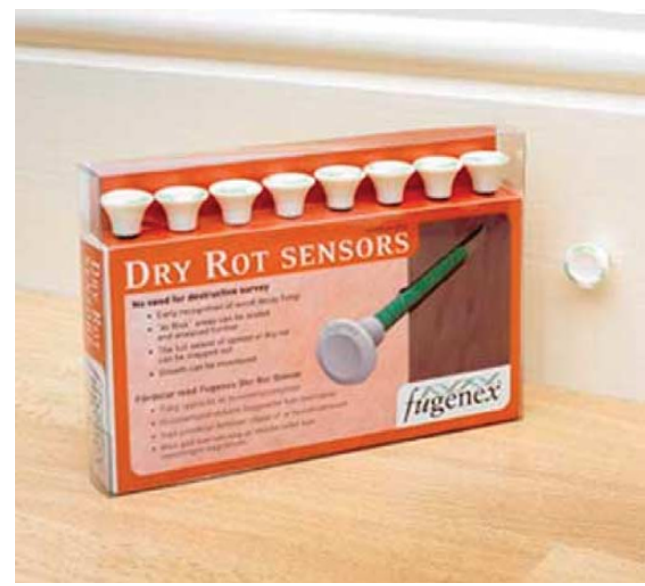

Figure 1: The commercial product supplied by Fugenex

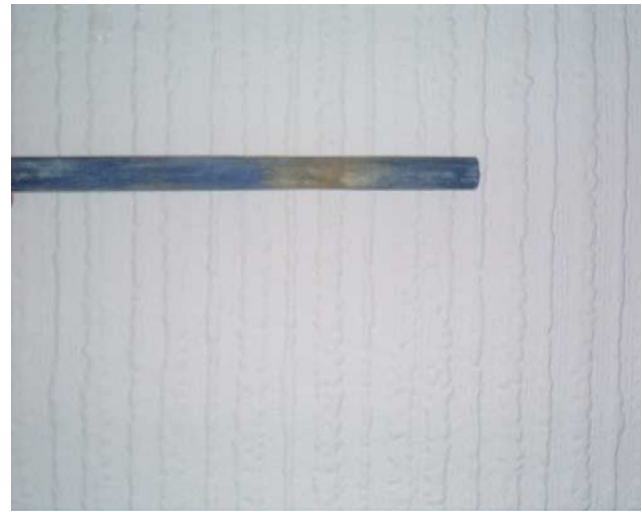

Figure 2: Sensor that has given a positive indication of dry rot

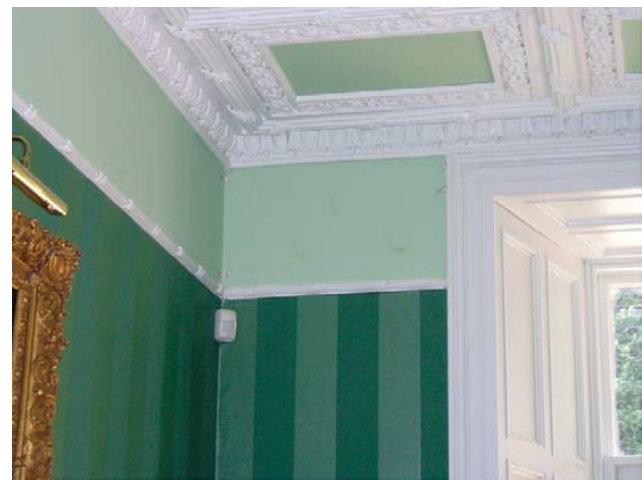

Figure 3: Sensors mapping out the spread of dry rot in a room adjacent to an established outbreak of dry rot

Such information is required when carrying out a detailed survey of a building or when an outbreak of dry rot has been discovered and it is necessary to map out the full extent of the spread of dry rot without the normal disruption of lifting floors and removing plasterwork. 


\section{Anyone can use the sensors}

\section{Sensors in action}

\section{WHO CAN USE THE SENSORS?}

An important advantage in the application of dry rot sensors is that they can be fitted and examined by anyone. No specialised equipment is necessary. The sensors are simply fitted then removed for examination. The sensors can be used in conjunction with an electrical moisture meter for determining the spread of moisture when they are removed for examination.

After examination, sensors that have not reacted can be re-fitted for future examination. Sensors that have reacted may be replaced for future examination. If desired, this can form part of a long-term monitoring procedure, for example, in a historic building where it is desirable to deal with the dry rot using environmental control technology.

\section{A FEW EXAMPLES OF THE SENSORS IN ACTION}

First, a surveyor carrying out a routine inspection notices a damp, stained area that he thinks might give rise to dry rot. He advises his client that he wants to check it out and does so by fitting sensors. He gets either a 'yes, there is dry rot' or 'no, there is not' response.

Secondly, a surveyor finds dry rot in a roof void but cannot see how far it has spread into the room below. He can fit some sensors and will get a 'yes, there is dry rot' indication until the point where the dry rot stops.

Alternatively, he can map out the spread of moisture that will tell him the whole 'at risk' area, then examine the sensors and establish how far the dry rot has spread within that area. He has then established how far he has to go with his treatment in order to stop the dry rot from spreading further.

Thirdly, an area previously treated for dry rot becomes wet as a result of a flood from a pipe. Sensors can be fitted in the affected area allowing the moisture to be monitored until it dries out fully. As the area dries out the sensors can be checked to ensure that there is no dry rot redevelopment. Once dry there is no longer a risk and the sensors can be removed.

Finally, an outbreak of dry rot has spread behind some ornamental panelling in a historic building. To treat the outbreak using conventional methods would involve damage to the panelling. Sensors can be fitted within and around the affected area and the activity of the fungus monitored. Environmental control principles then can be applied and the sensors used to monitor the dying back of the fungus as the control takes effect. Subsequently, the sensors may be used as a regular or even permanent way of monitoring the area, all without damage to the historical artefacts.

\footnotetext{
References

Building Research Establishment (1993) Dry Rot: Its Recognition and Control, Digest 299, Building Research Establishment, Watford, UK.

Bricknell, J.M. (1976) BWPA Annual Convention Record, Surveying for Rot - A Specialist Approach, BWPA, London, UK.

Bricknell, J.M. (1991) 'Surveying to determine the presence and extent of an attack of dry rot within buildings in the United Kingdom', in Jennings, D.H. and Bravery, A.F. (eds) Serpula lacrimans: Fundamental Biology and Control Strategies, John Wiley and Sons, Chichester, UK.

Bech-Andersen, J. (1995) The Dry Rot Fungus and Other Fungi in Houses, DK2840, Hussvamp Laboratoriet, Holte, Denmark.
} 
Esser, P.M. and Tas, A.C. (1992) Detection of Dry Rot by Air Analysis. International Research Group on Wood Preservation Document IRG/WP/2399, IRG, Stockholm, Sweden.

Lloyd, H. and Singh, J. (1994) 'Inspection monitoring and environmental control of timber decay', in Singh, J. (ed.) Building Mycology E. \& F.N. Spon, London, UK.

Peek, R.D., Willeitner, H. and Harm, U. (1980) 'Farbindikatoren zur Bestimmung von Pilzbefall im Holz', Holz als, Roh-Und Werkstoff, 38, 225-9.

Rypacek, V. (1966) Biologie Holzzerstorender Plize, 1st edn, Jena VEB G. Fisher.

Willeitner, H. and Peek, R.D. (1979) 'Colour reaction for detecting fungal attack in wood', International Journal of Wood Preservation, 1, 47-8. 